RESEARCH ARTICLE

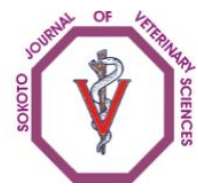

Sokoto Journal of Veterinary Sciences

(P-ISSN 1595-093X/ E-ISSN 2315-6201)

Egbetade et al/Sokoto Journal of Veterinary Sciences (2014) 12(3): 26-31

http://dx.doi.org/10.4314/sokjvs.v12i3.5

\title{
Gastrointestinal helminths of resident wildlife at the Federal University of Agriculture Zoological Park, Abeokuta
}

\author{
A Egbetade ${ }^{1}$, O Akinkuotu ${ }^{2}, \mathrm{O} \mathrm{Jayeola}^{3}, \mathrm{~A} \mathrm{Niniola}^{1}, \mathrm{~N} \mathrm{Emmanuel}^{4}, \mathrm{E} \mathrm{Olugbogi}^{2}$ \& S \\ Onadeko $^{3}$
}

1. Department of Veterinary Medicine \& Surgery, College of Veterinary Medicine, Federal University of Agriculture Abeokuta, Ogun State- Nigeria.

2. Department of Veterinary Microbiology and Parasitology, College of Veterinary Medicine, Federal University of Agriculture Abeokuta, Ogun State- Nigeria.

3. Department of Forestry and Wildlife, College of Environmental Resources, Federal University of Agriculture Abeokuta, Ogun State- Nigeria.

4. Federal University of Agriculture Zoological Park Abeokuta, Ogun State- Nigeria.

*Correspondence: Tel.: +2348034012916, E-mail: egbetadeao@funaab.edu.ng

\begin{abstract}
A total of forty two resident animals representing eighteen wildlife species at the Federal University of Agriculture (FUNAAB) Zoo Park were screened for nematode helminths between May and June 2013. Freshly voided faeces from the animals were subjected to basic coprology tests (Direct Microscopic Examination and Concentration Techniques). Trichuris specie. was the most prevalent nematode in primate species. Prevalence of $14.3 \%$ and 28.6\% were recorded for Capillaria specie and Strongyles in the primates respectively. A prevalence of $100 \%$ infection with nematodes in screened fourteen (14) primates was recorded. Mona and Vervet monkeys have the highest points for parasite richness count of 2 out of 3 detected nematodes amongst the primates. Wild birds at the park recorded the lowest prevalence for any type of nematodes with 7 out of 8 species without any nematode detected. Ascaridae was only detected in carnivorous reptiles and birds. In terms of feeding category, carnivorous species namely the (Aquila spilogaster) and Royal python ( $P$. regius) have the highest species richness count of parasites. Non-nematode helminths detected include protozoons (Isospora and Eimeria) and Cestodes segments suspected to be Echinococcus proglotids. Knowledge of the helminth parasites in wild animals is vital in formulating preventative veterinary protocols in captive exhibits. This is the first documented account of nematode helminths of resident wild animals at the FUNAAB Zoo Park, Abeokuta.
\end{abstract}

Keywords: Helminth, Nematodes, Parasite richness count, Wild animals, Zoo

Received: 25-09-2013

Accepted: 12-08-2014

\section{Introduction}

Captive-held wild animals are those housed in zoological exhibits, rehabilitation centers, zoos, research stations, sanctuaries, aquaria, circuses, and plantations. These animals are kept for purposes like education, entertainment, relaxation, research, cultural, transportation, labour and preservation of endangered species. Parasites have been incriminated as capable of causing unthriftness and ill health in captive and free ranging wildlife (Gillespie, 2006; Emikpe et al., 2007; Milozzi et al.,
2012) In Nigeria there is still a lacuna of data on the diseases and parasites harboured by wild animal in captive and wild settings. Wildlife plays important roles as sources, reservoirs, and amplifiers of emerging human and livestock pathogens (Daszak et al., 2000; Greger, 2007). Diseases in wild animals pose not just health risks but enormous economic impacts with emotional and health risks involved. Infectious diseases are the third most important driver of population decline of wildlife (Daszak, 
2000; Bengis et al., 2004; Gillespie, 2006) after hunting and habitat degradation. However, there is a dearth of information on diseases and parasites of zoo animals to reveal the transmission and impacts of pathogens of human origin (Hopkins \& Nunn, 2007) especially protozoan, helminth and arthropod parasites of wildlife (Gillespie et al., 2004; Friant, 2007). This is a major limiting factor in health management of zoological exhibits (Hotez et al., 2008; Thompson et al., 2010).

Zoological animals cover a wide array of species, and are thus susceptible to infections of closely related species of livestock, domestic and humans. This interlink in disease emergence has been captured as essential (Gillespie et al., 2008, Calvignac-Spencer et al., 2012) and has led to coinages like "pathogen pollution" (Daszak et al., 2000) "spill over and spill back" in wildlife disease epidemiology and inter phases with humans and other animals.

Wild animals have been documented to suffer from a plethora of common or shared pathogens with humans and livestock. Due to their proximity to each other within the zoological garden, there is opportunity of transmitting diseases or parasites to species which would not normally come into contact with the pathogens and thus are highly susceptible to infection (Bengis et al., 2004; Emikpe et al., 2007) Wild animals in captivity may harbour helminth parasites at sub-clinical infection levels. Low level parasitic infestations have been noted to reduce populations in the wild by reduction of vigour in affected species (McCallum \& Dobson, 1995; Dagnachew et al., 2011). Parasitic infections have been noted to induce subtle local decline in abundance Incidence and or prevalence of helminth parasites have been documented in wild animals; grevy zebras (Mouria et al., 2005), grasscutters (Opara \& Fagbemi, 2008) non-human primates (Hahn, 2003; Pedersen 2005; Ryan et al., 2012), birds and other zoo animals (Parasani, 2003; Ajibade et al., 2010; Opara et al., 2010; Milozzi, 2012).

Nematode helminths impart negatively on the conservation and health of wildlife (Pedersen et al., 2005; Gillespie, 2006; Hotez et al., 2008). Although it is possible for helminths to coexist with wildlife without obvious pathology (Krief et al., 2010; Ryan et al., 2012) however in some instances, consequent pathology may be more severe (Emikpe et al., 2002; Emikpe et al., 2007; Muller et al., 2010). The stress of captivity and contiguity to humans (Woodford et al., 2002; Wenz et al., 2009) may also contribute to how resistant these animals will be to parasites in captivity.

Routine faecal parasitology screening is thus very important in zoological collections. It is also critical to have base-line information on the helminth flora of these animals, these invariably helps in formulating preventative protocols.

Information on the diseases and parasites of wild animals in Nigeria is scanty compared to East and South Africa (Hopkins \& Nunn, 2007; Hotez et al., 2008). This inadequate information and documentation on diseases and parasites of zoo animals is a major limiting factor in veterinary medical management in zoological gardens This is the first survey of gastro-intestinal parasites of animals at FUNNAB Zoo Park (FZP).

\section{Materials and methods}

Captive wild animals (Table 1 ) residing at the FUNAAB Zoo Park (FZP) located along \{latitude70 13' 15" N; longitude 3 26' 51" E; $181 \mathrm{~m}$ \} Abeokuta were enlisted for this survey. The FUNAAB Zoo Park (FZP) was commissioned on the 23rd May 2012. The FZP is managed by Zoo Directorate, FUNAAB. Permission to collect samples was sought for from the Zoo Directorate.

\section{Sample collection and preservation}

Freshly voided faeces were collected from the animals at the zoos between March and June, 2013 with assistance of the animal handlers. The sample collection did not in any way impact negatively on the welfare of the study subjects. The topmost part of the faeces was scooped to prevent contamination. A clean black nylon was spread under free standing bird cages to collect faeces on dropping. Faeces collected was stored in well labelled $30 \mathrm{ml}$ sample bottles and kept in cool box- transport medium containing ice packs to the laboratory for preservation and analysis at the Parasitology laboratory of the College of Veterinary Medicine, FUNAAB. The mode of preservation of the samples was a two-way storage: in refrigerator at $4^{\circ} \mathrm{C}$ and in $10 \%$ formalin.

\section{Faecal analysis}

Faeces were grossly examined for species-specific consistency, colour and presence of proglottids and adult worms.

Direct microscopic examination (quick method) was done by placing a very small quantity of faecal dropping on a glass slide using a tooth pick and emulsify with a drop of water and place a cover slip to view on the microscope (Suwansaksri et al., 2002). Concentration techniques enlisted were-Formol ethyl acetate sedimentation method (Moges et al., 2010) and Simple Salt $(\mathrm{NaCl})$ Floatation as described by Gillespie (2006) and Parameshwarappa et al. (2012). Presence of helminth ova was recorded and expressed as a percentage of samples screened for 
species and amongst orders. Parasite richness count for primate species was deduced by counting the number of nematode helminths discovered in the different species (Gillespie, 2006).

\section{Results}

In this study, Trichuris specie. (Plate I) is the most prevalent nematode in non-human primate (NHP) species (75\% for species and $57 \%$ for individuals) (Table 2). Prevalence of $14.3 \%$ and $28.6 \%$ was recorded for Capillaria specie. (Plate II) and Strongyles respectively in the NHPs. A prevalence of $100 \%$ infection with nematodes in fourteen (14) screened primates was recorded. Mona and Vervet monkeys have the highest points for parasite richness count of 2 out of 3 detected nematodes amongst the primates (Table 3 ). Wild birds at the park recorded lowest prevalence for any type of nematode; with only 7 out of 8 species having detectable nematodes ova in faeces. Ascaridae (Plate III) was only detected in carnivorous reptiles and birds. In terms of feeding category, carnivorous species namely the African Hawk-eagle (Aquila spilogaster) and Royal python ( $P$. regius) have the highest species richness count of parasites (Table 4). Non-nematode helminths detected include protozoas (Isospora and Eimeria) and Cestodes (Echinococcus proglotidds).

Table 1: Resident animals in FUNAAB Zoo Park

\begin{tabular}{llllll}
\hline Common name & Scientific name & Numbers & Common name & Scientific name & Numbers \\
\hline Olive baboons & Papio Anubis & 3 & Red throated robin & Pethroica goodenovii & 2 \\
Patas monkey & Erythrocebus patas & 6 & Eagle & & 1 \\
Mona monkey & Cercopithecus mona & 3 & Ring nose parakeet & Psittacula krameri & 2 \\
Vervet monkey & Cercopithecus aethiops & 2 & Crocodiles & Osteolemus niloliticus & 3 \\
Jackal & Canis aureus & 2 & Tortoises & Geochelone sulcata & 1 \\
Hyena & Croucuta croucuta & 2 & Turtle & Testudine spp & 5 \\
Ostriches & Struthio camelus & 2 & Puff adder & Bitis arietans & 1 \\
African grey parrots & Psittacus erithacus & 2 & Royal python & Python regius & 1 \\
Crowned cranes & Balearica regulorum & 2 & Monitor lizard & Veranus niloticus & 2 \\
Geese & Chen caerulescens & 4 & & & \\
Red headed love bird & Agapornis pullarius & 2 & & & \\
\hline
\end{tabular}

Table 2: Parasite richness count and prevalence of nematodes in non-human primate species

\begin{tabular}{lllll}
\hline Order & Species(No) & Parasite ova identified & Prevalence (\%) & Parasite richness count \\
\hline Primates & E. patas (6) & Strongyle, & $3 / 6(50 \%)$ & $1 / 3$ \\
& C. aethiops (2) & Trichuris & $2 / 2(100 \%)$ & $2 / 3$ \\
& & Capillaria & $2 / 2(100 \%)$ & \\
& C. mona (3) & Trichuris & $3 / 3(100 \%)$ & $2 / 3$ \\
& P. anubis (3) & Strongyle & $1 / 3(33 \%)$ & \\
& & Trichuris & $3 / 3(100 \%)$ & $1 / 3$ \\
\hline
\end{tabular}

Table 3: Prevalence of nematodes within the individual Non-human primates at the FUNAAB Zoo Park

\begin{tabular}{|c|c|c|c|c|c|}
\hline $\begin{array}{l}\text { Nematodes } \\
\text { detected }\end{array}$ & E. patas & P. anubis & C. mona & C. aethiops & $\begin{array}{l}\text { Total } \\
\text { prevalence (\%) }\end{array}$ \\
\hline Trichuris & $0 / 6$ & $3 / 3$ & $3 / 3$ & $2 / 2$ & $8 / 14(57.1 \%)$ \\
\hline Capillaria & $0 / 6$ & $0 / 3$ & $0 / 3$ & $2 / 2$ & $2 / 14(14.3 \%)$ \\
\hline Strongyle & $3 / 6$ & $0 / 3$ & $1 / 3$ & $0 / 2$ & $4 / 14(28.6 \%)$ \\
\hline Order/Class & & Species/ (1 & & \multicolumn{2}{|c|}{ Parasite ova identified } \\
\hline \multirow[t]{3}{*}{ Reptilia } & & Python res & & \multicolumn{2}{|c|}{ Ascaris, Oxyuris, Kalicephalus ova } \\
\hline & & C. chamel & & \multicolumn{2}{|c|}{ NOS } \\
\hline & & G. sulcata & & \multicolumn{2}{|l|}{ NOS } \\
\hline \multirow[t]{3}{*}{ Aves } & & Acipitrida & & \multicolumn{2}{|l|}{ Ascaris spp } \\
\hline & & S. camelus & & \multicolumn{2}{|l|}{ NOS } \\
\hline & & B. regulor & & \multicolumn{2}{|l|}{ NOS } \\
\hline
\end{tabular}

NOS: No ova seen 


\section{Discussion}

Results from this study shows that the zoo animals at the FZP harbour parasites which are not novel to science (Milozzi et al., 2012; Ryan et al., 2012; Okpara et al., 2010) but are of importance to their health and also the development of a staff' health protocol especially with the presence of Trichuris specie (Plate I)

Non-invasive studies of wildlife parasites can readily provide data on presence or absence, richness, and prevalence of parasitic infections, thus should not report intensity (Gillespie, 2006). The assessment of health status of most captive wildlife in Nigeria is based on evaluation of physical outlook. Although these animals appear healthy without any obvious signs of helminthosis, it is essential to monitor these trends as just physical appraisals could be misleading at times. Faecal parasitology offers an insight into their medical status.

Helminthosis in zoo animals is a manageable condition when proper chemo-prophylaxis and strict hygiene standards are adhered to. The prevalence recorded for most nematode identified is in tandem with previous studies (Opara et al., 2010; Milozzi et al., 2012).

The stress of captivity and contiguity to humans may also contribute to how resistant these animals will be to parasites in captivity. Most animals at the FZP do not display outward behaviours suggestive of stress.

Trichuris ova in Cercopithecus aethiops differ microscopically from others; this is probably in agreement with the demystification of Trichuris as one single worm specie or the presence of different ova types. C. aethiops has a mixed infection of Trichuris types as some ova also resemble the common Trichuris ova as seen in other primate species. The similarities between primates at the zoo in terms of feeding, phylogenetic closeness and contiguity of their housing at the FZP made them easy for comparable analysis. The prevalence recorded for Trichuris and Capillaria (Plate II) are however in concord with previous studies from literature (Ryan et al., 2012).

Trichuris specie. was the most prevalent nematode in primate species $(75 \%$ for species and $57 \%$ for individuals). Mona and vervet monkeys have the highest points for species richness of 2 out of 3 detected nematodes. An overall prevalence of $100 \%$ infection with nematodes in screened primates. Wild birds at the park recorded lowest prevalence for any type of nematode. Of all the classes of animal screened, carnivorous species namely the Black eagle (Accipitiridae spp) and Royal python ( $P$. regius) have the highest species richness count of parasites. None nematode helminths detected include protozoas (Isospora and Eimeria); Trematodes (Echinococcus proglotidds); mite Nortoedis.

Most infections among the carnivore are acquired from prey-predator perspectives. Ascarids have an indirect life cycle in most carnivorous and reptiles (Klingenberg, 2004). In the Royal python, ectopic parasitism could not be over ruled based on the feeding biology preferences. The oxyurids which have a direct life cycle must have been through faeco-oral route, likewise the mite (Nortoedres) might be as a result of the live animal (rabbit) presented as feed.

A low prevalence of helminthoses in the aviary could be attributed to the housing; the birds in most instances do not have access to their droppings- this breaks the cycle of transmission. Ostriches (Struthio camelus) at FZP have enough floor space and have created a spot to defecate which is far from their feeding spots. This contributed to the low prevalence of nematode helminths in these birds.

It is not advisable to hide under the comfort of endemicity to relent on routine testing in zoos as cross transmission of parasites or fulminating parasitosis secondary to immuno suppression or septicaemia may ensue. The zoo setting unarguably provides a platform for this. Choice of antihelminthic given was based on previous literatures and species specific dose rates and contraindications strictly adhered to.

The level of helminthosis is neither alarming nor unusual. This level is comparable to what is obtainable in most zoos (Varadharajan \& Kanadasamy, 2000; Okpara et al., 2010) The risks of transmission to the public is negligible once the recommended precautionary distances and attitudes when around the zoo is ensured.

Nematode helminths are prevalent in zoo collections and FZP is not an exemption. According to Krief et al. (2010), some helminths coexist with wildlife with no obvious pathology; also the screened animals at FZP did not show any clinical signs or pathology which suggests mild to moderate infection at sub clinical level. The current level of hygiene standard at FZP is adequate and should not be allowed to slip to prevent heavy helminth and other parasitic infection. However, accessibility to viable faecal samples remains a big factor militating against coprological studies in zoo animals. In order to ensure the well-being of staff, public and resident animals, routine testing and treatment of nematode helminthosis in zoo animals is very germane. 


\section{References}

Ajibade WA, Adeyemo OK \& Agbaje SA (2010). Coprological Survey and Inventory of Animals at Obafemi Awolowo University and University of Ibadan Zoological Gardens. World Journal Zoology, 5 (4): 266271.

Bengis RG, Leighton FA, Fischer JR, Artois $M$ \& Morner T, (2004). The Role of emerging and re-emerging zoonoses. Scientific and Technical Review World Organisation for Animal Health, 23 (2): 497-511.

Calvignac-Spencer S, Leendertz SJ, Gillespie TR \& Leendertz FH (2012) Wild great apes as sentinels and sources of infectious disease. Journal of Clinical Microbiology and Infection, doi: 10.1111/j.14690691.2012.03816.x

Dagnachew S, Amamute A \& Temesgen W (2011). Epidemiology of gastrointestinal helminthiasis of small ruminants in selected sites of North Gondar zone, Northwest Ethiopia. Ethiopian Veterinary Journal, 15(2)57-68.

Daszak P, Cunningham AA \& Hyatt AD (2000). Emerging Infectious Diseases of WildlifeThreats to Biodiversity and Human Health. Science, 287(5452): 443-449.

Emikpe BO, Ayoade GO, Ohore OG, Olaniyan OO \& Akusu MO (2002). Fatal trichuriosis in a captive baboon (Papio anubis) in Ibadan Nigeria: A case report. Tropical Veterinarian, 20(1): 36-39.

Emikpe BO, Adeniran GA, Alaka OO, Ohore OG, Antia RE, Ajayi OL \& Omobowale OT (2007). Valvular endocarditis in a captive monkey in Ibadan Nigeria: a case report. Nigerian Veterinary Journal, 28(3): 49-52.

Gillespie TR, Nunn C \& Leendertz FH (2008). Integrative Approaches to the Study of Primate Infectious Disease: Implications for Biodiversity Conservation and Global Health. American Journal of Physical Anthropology, 137(S47): 53-69.

Gillespie TR (2006). Non-invasive Assessment of Gastrointestinal Parasite Infections in FreeRanging Primates International Journal of Primatology 27(4): 1129-1143.

Gillespie TR, Greiner EC \& Chapman CA (2004). Gastro-intestinal parasites of guenons of Western Uganda. Journal of Parasitology, 90(6) :1356-1360.
Greger M (2007). The Human/Animal Interface: Emergence and Resurgence of Zoonotic Infectious Diseases. Critical Reviews in Microbiology, 339(4): 243-299.

McCallum H \& Dobson A (1995). Detecting disease and parasite threats to endangered species and ecosystems Trend in ecology and evolution 10(5):190-194.

Hahn NE, Proulx D, Muruthi PM, Alberts S \& Altmann $J$ (2003). Gastrointestinal Parasites in Freeranging Kenyan Baboons (Papio cynocephalus and $P$. anubis). International Journal of Primatology, 24(2): 271-279.

Hopkins ME \& Nunn CL (2007). A global gap analysis of infectious agents in wild primates. Diversity and Distributions. 13(5): 561-572.

Hotez PJ, Brindley PJ, Bethony JM, King CH, Pearce EJ, \& Jacobson J (2008). Helminth infections: the great neglected tropical diseases The Journal of Clinical Investigation 118 (4): 1311-1321.

Krief S, Vermeulen B, Lafosse S, Kasenene JM, Nieguitsila A, L'Hostis M, Bain O \& Guillot J (2010). Nodular Worm Infection in Wild Chimpanzees in Western Uganda: A Risk for Human Health. PLoS Neglected Tropical Diseases 16;4(3):e630.

Klingenberg RJ, (2004). Reptile Parasitology In: British small animal veterinary association manual of reptiles, $2^{\text {nd }}$ edition, (Girling JS \& Raiti $P$, editors), British Small Animal Veterinary Association, Gloucester, UK Pp 319-329.

Milozzi C, Bruno G, Cundom E, Mudry MD \& Navone GN (2012). Intestinal Parasites of Alouatta caraya (Primates, Ceboidea): Preliminary Study in Semi-Captivity and in the Wild in Argentina Mastozoologia Neotropical http://www.sarem.org.ar retrieved, 19-052013.

Moges F, Belyhun Y., Tiruneh M., Kedebe Y., Mulu A, Kassu A and Huruy K (2010) Comparison of formol-acetone concentration method with that of the iodine preparation and formolether concentration methods for examination of stool parasites Ethiopian Journal of Health Development 24(2): 148151

Müller B, Mätz-Rensing K, Pérez Yamacita JG \& Heymann EW, (2010) Pathological and parasitological findings in a wild red titi monkey, Callicebus cupreus (Pitheciidae, 
Platyrrhini) European Journal Wildlife Research, 56(4): 601-604.

Opara MN \& Fagbemi BO (2008). Occurrence and Prevalence of Gastrointestinal Helminthes in the Wild Grasscutter (Thryonomys swinderianus, Temminck) from Southeast Nigeria, Life Science Journal. 5(3): 50-56.

Opara MN, Osuji CT \& Opara JA (2010). Gastrointestinal parasitism in captive animals at the Zoological Garden, Nekede Owerri, Southeast Nigeria. Report and Opinion, 2(5): 21-28.

Parasani HR, Momin RK, Sahu \& Patel BG (2003). Prevalence of Gastrointestinal Parasites in Captive Birds at Kamla Nehru Zoological Garden Kankaria Zoo Ahmedabad Gujarat Zoo's Print Journal, 18 (1): 987-922.

Pedersen AB, Altizerb $S$, Possc $M$, Cunningham AA \& Nunne CL (2005). Patterns of host specificity and transmission among parasites of wild primates. International Journal for Parasitology, 35(6):647-657.

Ryan SJ, Brashares SJ, Walsh C, Milbers K, Kilroy C \& Chapman CA (2012). A Survey of Gastrointestinal Parasites of Olive Baboons (Papio anubis) in Human Settlement Areas of Mole National Park, Ghana. Journal of Parasitology 98(4): 885-888.

Suwansaksri J, Nithiuthai S, Wiwanitkit V, Soogarun S \& Palatho P (2002) The Formol-ether Concentration Technique for Intestinal Parasites: Comparing $0.1 \mathrm{n}$ Sodium Hydroxide with Normal Saline Preparations. Southeast Asian Journal of Tropical Medicine and Public Health 33(3): 97-98.

Thompson RCA, Lymbery AJ \& Smith A (2010). Parasites, emerging disease and wildlife conservation International Journal for Parasitology 40(10): 1163-1170.

Varadharajan A \& Kanadasamy A (2000). A Survey of Gastrointestinal Parasites of Wild Animals in Captivity in the V.O.C. Park and Mini Zoo, Coimbatore, Zoo's Print Journal, 15(5): 257258.

Wenz A, Heymenn WE, Petney TN \& Taraschewski HF (2009). The influence of human settlements on the parasite community in two species of Peruvian tamarind. Pp 675684.

Woodford MH, Butynski TM \& Karesh WB (2002). Habituating the great apes: the disease risks. Oryx 36: 153-160. 